PHYSICAL REVIEW B 72, 199901 (2005)

\title{
Publisher's Note: Meron excitations in the $\nu=1$ quantum Hall bilayer and the plasma analogy [Phys. Rev. B 72, 155306 (2005)]
}

Milica V. Milovanović and Ivan Stanić

(Received 25 October 2005; published 3 November 2005)

DOI: 10.1103/PhysRevB.72.199901

PACS number(s): 73.43.Cd, 73.43.Lp, 71.10.Pm, 99.10.Fg

This paper was published online on 11 October 2005 with an error in the placement of Figs. 3-8. The figure placements have been reformatted to correlate more closely with the location of their citations. The paper has been corrected as of 25 October 2005. The figure formatting is correct in the printed version of the journal. 